Article

\title{
A Two-Step Strategy for Developing Cultivated Pastures in China that Offer the Advantages of Ecosystem Services
}

\author{
Haibin Chen ${ }^{1,2}$, Li He ${ }^{1}$, Haiping Tang ${ }^{1, *}$, Minjuan Zhao ${ }^{2}$ and Liqun Shao ${ }^{2}$ \\ 1 College of Resources Science and Technology, Beijing Normal University, Beijing 100875, China; \\ hbchen@nwsuaf.edu.cn (H.C.); hl@mail.bnu.edu.cn (L.H.) \\ 2 College of Economics and Management, Northwest A\&F University, Yangling 712100, China; \\ minjuan.zhao@nwsuaf.edu.cn (M.Z.); skirtshao@nwsuaf.edu.cn (L.S.) \\ * Correspondence: tanghp@bnu.edu.cn; Tel.: +86-10-5880-2108; Fax: +86-10-5880-8555
}

Academic Editor: Marc A. Rosen

Received: 29 January 2016; Accepted: 18 April 2016; Published: 21 April 2016

\begin{abstract}
Based on a site experiment on a typical steppe of Inner Mongolia, the short term effects on aboveground biomass, soil water content, soil organic carbon, and soil total nitrogen of four cultivated pastures (CPs) with different compositions of herbaceous species were examined and compared to those of adjacent, natural grassland (NG) enclosed simultaneously. All CPs produced significantly higher aboveground biomass than did the NG after two years of establishment, and the mixed culture of Agropyron cristatum (A. cristatum) and Medicago sativa (M. sativa) produced the highest (312.39\% higher than the NG). Without irrigation, soil water content in the 10-20 cm soil layer was also found to be significantly higher in the CPs than in the NG, especially for the mixed cultures of A. cristatum and M. sativa, A. cristatum, M. sativa and Lolium perenne (L. perenne), by $184.25 \%$ and $125.97 \%$, respectively. The improvements in soil organic carbon and soil total nitrogen in CPs were less obvious and mixed, with different species compositions showing significant increases at different depths. The experimental results suggested that, with carefully selected species compositions and proper farming measures, CPs could have a positive effect on some of the pathways that generate ecosystem services, at least in the short term. We also analyzed the underlying institutional and socioeconomic causes of China's underdevelopment of CPs, and proposed a two-step development strategy. The first is to promote rain-fed CPs on small-hold farms, which require relatively low inputs in fertilizers and labor. The second is to promote large-scale operations, which will require significantly more inputs in land, irrigation, fertilizers, and machinery.
\end{abstract}

Keywords: cultivated pasture; ecosystem service; grassland enclosure; nature-based solutions

\section{Introduction}

Grassland in China, which covers an area of 400 million ha and accounts for $41.7 \%$ of the total land area, is acknowledged as the dominant landscape [1]. For centuries, grassland has provided forage for livestock. Today, its role in providing a variety of other ecosystem services, such as biodiversity, soil and water conservation, carbon sequestration, a repository of genetic resources, etc., is recognized increasingly by the academic community and policymakers [2,3]. However, over $90 \%$ of grassland in China is degraded, or in the process of becoming degraded [4]. Grassland degradation of this magnitude may be responsible for several regional, and even global, environmental problems, including desertification, salinization, pest outbreaks, and frequent dust storms [5]. For example, grassland degradation in Inner Mongolia is believed generally to be a major reason for the increased frequency of severe sand and dust storms in northern China in recent decades, particularly in Beijing 
and adjacent regions [6]. In addition, such degradation also has a direct effect on the livelihood of millions of people who have inhabited the region for generations [7].

Overgrazing is recognized as a major course of grassland degradation in China [8], and one proposed method to restore grassland vegetation is to fence it off to prevent human encroachment, and rely totally on the system's ability to recover naturally [9]. Since 2000, China has implemented several nationwide grassland ecological restoration projects, and encouraged the cessation of grazing. These projects include the Grassland Enclosure and Ecological Migration Project, Return Grazing Land to Grassland Project, and the Subsidy and Reward System for Grassland Ecological Protection [10]. However, discontinuing grazing conflicts with the development of animal husbandry, which cannot be compromised because of rapid economic growth and improvements in the standard of living. Moreover, livestock production is often the only source of livelihood for people who live in grassland regions. Consequently, most herders have turned to breeding livestock in captivity, and grow grasses or forbs as an alternative source of forage in areas with benign water and soil conditions. On the other hand, according to the grazing optimization hypothesis, an appropriate level of grazing intensity is needed and can contribute to enhance biodiversity and primary productivity [11]. A controlled experiment on a typical steppe of Inner Mongolia also suggested that a moderate stocking rate encouraged the complementary growth of plants and sustainable use of grassland, verifying the grazing optimization hypothesis [12]. Hence, grazing cessation is hardly a viable solution. A better strategy is to promote the synergy between an optimum level of grazing intensity and establishment of cultivated pasture.

At present, there is not a generally accepted definition and scope for cultivated pasture, and different terminologies are used to represent the concept, such as tame grassland, artificial grassland, sowing grassland, and seeding grassland. Nonetheless, these land use types share a common feature, in that humans manage them so intensively that they are more akin to cultivated lands than to rangelands. In the US, grasslands are classified into two general categories, pasture or pastureland, and rangeland. In a strict sense, the former are distinguished from the latter by being managed through more intensive agricultural practices of seeding, irrigation, and the use of fertilizers, while the latter grow primarily native vegetation, managed with extensive practices such as controlled burning and regulated intensity of grazing. In view of the discussion above, we used the term "cultivated pasture" for our purposes, and defined it as a herbaceous community established deliberately by sowing seeds of grasses, legumes, or other forbs, or a grass-forb mixture, on native vegetation that has been destroyed completely, assisted by one or a combination of farming measures, including plowing, sowing, irrigation, and fertilizing, etc.

Since the 1940s, developed countries have shifted to varying degrees from open grazing to planting cultivated pastures and grassland farming [13]. Trifolium-L. perenne mixed culture was a practice adopted widely in Europe [14]. To date, cultivated pasture in Europe accounts for more than $50 \%$ of the total grassland area, while forage from grassland accounts for $49 \%$ of total fodder. In the US, there are 31.5 million ha of permanent cultivated pastures that constitute $13 \%$ of the total grassland. If added to the grassland in ley farming, this figure increases to $29 \%$. In New Zealand, there are 9.46 million ha of cultivated pasture that account for $69.1 \%$ of total grassland. Livestock fodder depends almost entirely on the production of forage from grassland. Because of grasslands' high efficiency in forage production, the output of animal husbandry in developed countries generally accounts for $60 \%-80 \%$ of agriculture [15].

In 1984, the Chinese government began to encourage farmers to establish cultivated pastures. However, compared to natural grassland, the area of cultivated pasture is still much smaller. In 1995, it was 13.8 million ha, which is only $3.4 \%$ of all grassland. It increased to 15.48 million ha in 1997, and 20 million ha in 2000, and accounts for $3.8 \%$ and $4.8 \%$ of the total grassland, respectively [16]. However, this figure has decreased in recent years to only 13 million ha in 2005. Meanwhile, China's output of animal husbandry accounts for only $30 \%$ of agricultural output, of which grassland animal husbandry accounts for no more than 5\% [17]. According to the Grass Industry Sustainable 
Development Strategy released by the Ministry of Agriculture of China, the goal for the establishment of cultivated pasture is 30 million ha by 2020 , which will account for approximately $7.5 \%$ of the total grassland area [17].

Although the establishment of cultivated pasture is expected to enhance grassland ecological rehabilitation and sustainable economic development, its short- and long-term effects on forage production and provision of other ecosystem services need to be verified. In 2011, China's Ministry of Science and Technology launched a demonstration project of cultivated pasture establishment in Duolun County, Xilingol League, Inner Mongolia, in collaboration with scientists from Beijing Normal University, including the authors. The goal of this project was to establish a total of $5000 \mathrm{mu}$ (approximately $333 \mathrm{ha}, 1 \mathrm{mu}$ is equal to $0.067 \mathrm{ha}$ ) of demonstration fields in the following years, and a $1000 \mathrm{mu}$ monoculture of $A$. cristatum, $200 \mathrm{mu}$ monoculture of $M$. sativa $200 \mathrm{mu}$ mixed culture of A. cristatum and M. sativa, and a $200 \mathrm{mu}$ mixed culture of A. cristatum, M. sativa, and L. perenne were firstly established on 30 May 2011. We carried out observations on these four plots to examine the exact short- and long-term effects of cultivated pastures with different species compositions on various ecosystem services, with the former the research objective of this article.

The Millennium Ecosystem Assessment classifies all ecosystem services into four types: provisioning, regulating, supporting, and cultural [18]. In consideration of the major environmental problems confronting the experimental site, namely forage shortage, water scarcity, and frequent dust storms, we selected aboveground biomass production (AGB) as an indicator of provisioning services, soil water content (SWC) and soil organic carbon (SOC) as two indicators of regulating services, and total nitrogen (STN) as an indicator of supporting services. Because of a lack of data, we did not consider cultural services in this research. AGB is a direct indicator of forage yield, which is an indispensable service for local animal husbandry. SWC indicates the water holding capacity of grassland, which contributes to regulate water flow and provides both water supply and drought mitigation services for the region. SOC constitutes a primary portion of carbon sink in grassland, which provides an important global climatic regulation service. Both SWC and SOC can influence soil structural stability, which provides dust storm mitigation services for the region. Finally, sufficient STN supports healthy and sustainable growth of ground vegetation.

This study included two research objectives: First, to examine the short-term (two-year) effects of cultivated pastures by comparing the differences in the above-mentioned four ecosystem services supplied by cultivated pastures and adjacent, natural grasslands enclosed simultaneously on the typical steppe of Inner Mongolia. Second, in the Discussion Section, in addition to discussing the experimental results, we also analyzed the underlying institutional and socioeconomic causes of the underdevelopment of China's cultivated pastures, and then used this analysis as a basis to propose a practical, feasible, and sustainable two-step development strategy. The experiments and their results were regarded as a proof or precondition for the strategy proposed.

\section{Materials and Methods}

\subsection{Site Description}

The experimental site is located in Duolun County, Xilingol League of Inner Mongolia $\left(41^{\circ} 45^{\prime}-42^{\circ} 39^{\prime} \mathrm{N}, 115^{\circ} 30^{\prime}-116^{\circ} 55^{\prime} \mathrm{E}\right)$, at an altitude of $1150-1800 \mathrm{~m}$. The site occupies a transition region from the mid-temperate, sub-arid zone to the sub-humid zone, and is characterized by a continental climate, with a large daily temperature difference in the summer, and a freezing winter. The average annual precipitation and evaporation capacity from 1954 to 2009 were $382 \mathrm{~mm}$ and $1748 \mathrm{~mm}$, respectively, and the precipitation between June and August accounts for $70 \%$ of the annual precipitation. The annual mean air temperature is $2.3^{\circ} \mathrm{C}$, with the highest monthly mean temperature $\left(19.0^{\circ} \mathrm{C}\right)$ in July, and the lowest $\left(-17.5^{\circ} \mathrm{C}\right)$ in January. The soil properties in Duolun County can be classified into 7 types, including chestnut soil, aeolian sandy soil, meadow soil, chernozem soil, boggy soil, saline soil, and gray cinnamonic soil. Among all 7 soil types, chestnut soil is distributed 
most widely, and accounts for $70.26 \%$ of the total land area in the county. The vegetation is that of the mid-temperate steppe, and includes the dominant species of Leymus secalinus and Stipa krytovii, combined with a meadow steppe with constructive species of Leymus secalinus and Bromus inermis. The former are distributed widely on flat terrain and dark chestnut soil, while the latter are distributed largely on gentle slopes or high platforms, both of which have better soil water content.

The four cultivated pasture plots established in 2011 were included in our study as four treatments, and one plot of adjacent natural grassland was chosen as the control field. All five plots were subjected previously to open grazing. After cultivated pastures were established, the control field was fenced off for natural regeneration. The cultivated pastures were sown in lines, with an average line interval of $18.5 \mathrm{~cm}$ and seeding depth of $2-3 \mathrm{~cm}$ for both monocultures and mixed cultures (Table 1). All cultivated pastures were rain-fed, but received an application of $80 \mathrm{~kg} / \mathrm{hm}^{2}$ compound fertilizer (ammonium phosphate) after plowing and before sowing only. The utilization pattern of cultivated pastures is designed to be mown for forage; however, no mowing was conducted before we collected the quadrat samples, because they were still in their growth stage.

Table 1. Seeding treatments.

\begin{tabular}{|c|c|c|}
\hline Treatments & Seeding Schemes & Seeding Methods \\
\hline$A c$ & Monoculture of A. cristatum & $22.5 \mathrm{~kg} / \mathrm{hm}^{2}$ of $A c$ seeds were sown \\
\hline Ms & Monoculture of M. sativa & $22.5 \mathrm{~kg} / \mathrm{hm}^{2}$ of $M s$ seeds were sown \\
\hline$A c+M s$ & Mixed culture of $A$. cristatum and $M$. sativa & $\begin{array}{l}22.5 \mathrm{~kg} / \mathrm{hm}^{2} \text { of seeds were sown, with } \\
\text { Ac and } M s \text { accounting for } 50 \% \text { each }\end{array}$ \\
\hline$A c+M s+L p$ & $\begin{array}{l}\text { Mixed culture of A. cristatum, M. sativa, } \\
\text { and L. perenne }\end{array}$ & $\begin{array}{l}22.5 \mathrm{~kg} / \mathrm{hm}^{2} \text { of seeds were sown, with } \\
A c, M s \text {, and } L p \text { accounting for } 1 / 3 \text { each }\end{array}$ \\
\hline
\end{tabular}

Through a focus group discussion with ecologists and grass scientists, we chose three endemic perennial species for planting. A. cristatum is a high quality wild grass for local livestock. M. sativa is a high performance forage legume that has been promoted long-term and adopted widely throughout China's grassland regions. L. perenne is used typically for conservation tillage. Hence, we established a plot of $A$. cristatum to examine the effects of a wild grass monoculture, a plot of $M$. sativa to test the effects of a forage legume monoculture, a plot of $A$. cristatum and $M$. sativa to examine the effects of a mixed culture of a wild grass and a forage legume, and a plot of A. cristatum, M. sativa, and L. perenne to examine the effect of a mixed culture of a wild grass, legume, and conservation tillage grass.

\subsection{Sampling and Analysis}

Quadrat surveys were carried out on 20 August 2013. Three $1 \mathrm{~m} \times 1 \mathrm{~m}$ quadrats were selected randomly in each of four treatments and the control field.

For AGB, we collected 1 sample in each quadrat for a total of 15 samples. We clipped all above ground stems and leaves, and both litter and standing dead material were collected and sealed in plastic bags. All matter was dried in a $105^{\circ} \mathrm{C}$ oven to be deactivated, and then dried in a $65^{\circ} \mathrm{C}$ oven for $24 \mathrm{~h}$. The dried matter was weighed to determine biomass production $\left(\mathrm{g} / \mathrm{m}^{2}\right)$.

The coring method was used to collect soil samples. For SWC, 5 soil layers were collected at different depths $(0-10 \mathrm{~cm}, 10-20 \mathrm{~cm}, 20-30 \mathrm{~cm}, 30-40 \mathrm{~cm}$, and $40-50 \mathrm{~cm})$, for a total of 75 samples. Both fresh weight (FW, g) and dry weigh (DW, g) were measured, and SWC (\%) was calculated according to Equation (1):

$$
S W C=\frac{F W-D W}{F W} \times 100 \%
$$

For SOC and STN, 3 soil layers $(0-10,10-20$, and 20-30 cm) were collected for a total of 45 samples per indicator. All samples were air-dried and then sieved through a 2-mm screen. The potassium dichromate $\left(\mathrm{K}_{2} \mathrm{Cr}_{2} \mathrm{O}_{7}\right)$ oxidation heating method was used to measure the SOC $(\mathrm{g} / \mathrm{kg})$, and the Semimicro-Kjeldahl method was used to measure the STN $(\mathrm{g} / \mathrm{kg})$. 


\subsection{Data Analysis}

We used SPSS 18.0 to perform a single-factor analysis of variance (ANOVA) to test the differences in all four indicators among the four treatments and the control field. Mapping was conducted with Origin 8.0 software.

\section{Results}

\subsection{Forage Yield (AGB)}

The forage yield in all four types of cultivated pastures was statistically significantly higher than that in the adjacent enclosed natural grassland after two years of establishment, in which the mixed culture of A. cristatum and M. sativa produced the highest, with an average of $766.34 \mathrm{~g} / \mathrm{m}^{2}, 312.39 \%$ higher than the natural grassland $(p<0.05)$. The forage yield of the A. cristatum monoculture, which was, on average, $283.33 \%$ higher than that of the natural grassland, also was significantly different $(p<0.05$ : see Figure 1).

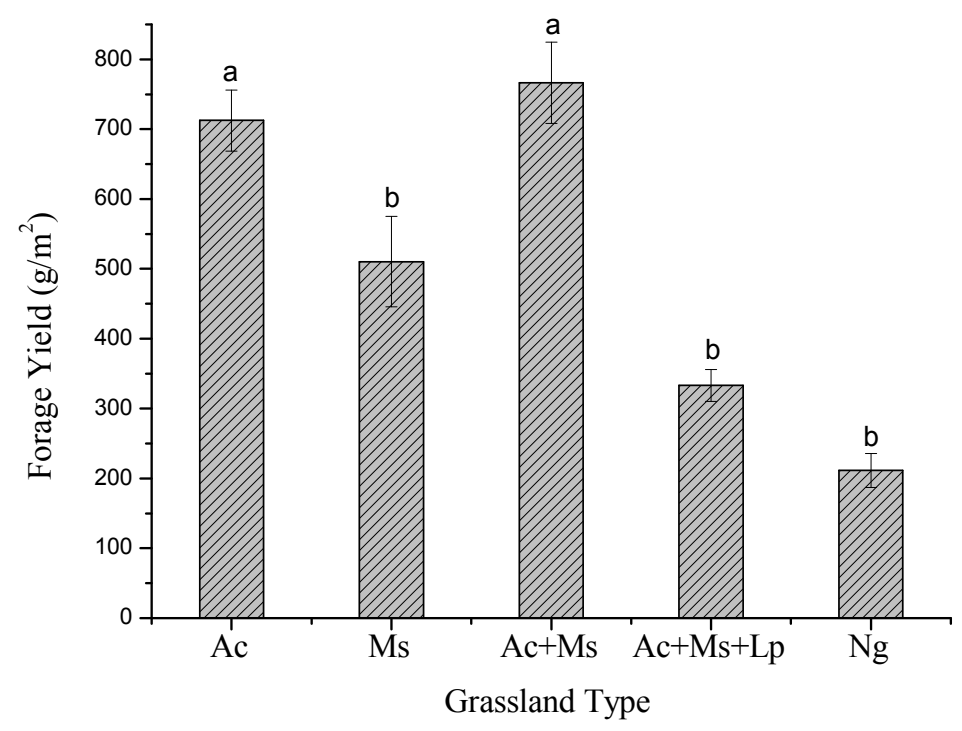

Figure 1. Effect of establishment of cultivated pastures on forage yield. $\mathrm{Ng}$ denotes the enclosed natural grassland control. Letters indicate significant differences between groups $(p<0.05)$. The same symbols also are used in the following figures.

\subsection{Soil Water Content}

As shown in Figure 2, the SWC for the different types of grasslands varied greatly in all five soil layers. The mixed culture of A. cristatum and M. sativa and of A. cristatum, M. sativa, and L. perenne produced a significant improvement in SWC. In the 10-20 cm soil layer in particular, the SWCs in these two mixed culture fields were $184.25 \%$ and $125.97 \%$ higher than that in the adjacent enclosed natural grassland, respectively $(p<0.05)$. The other two monocultures produced no significantly higher water-holding capacity in all soil layers, except layers $20-30 \mathrm{~cm}$ and $30-40 \mathrm{~cm}(p<0.05)$. It is noteworthy that, although the SWC in these two monoculture fields was not significantly higher overall than that in the natural grassland, it was practically higher in layers $0-10,10-20$, and $40-50 \mathrm{~cm}$. 


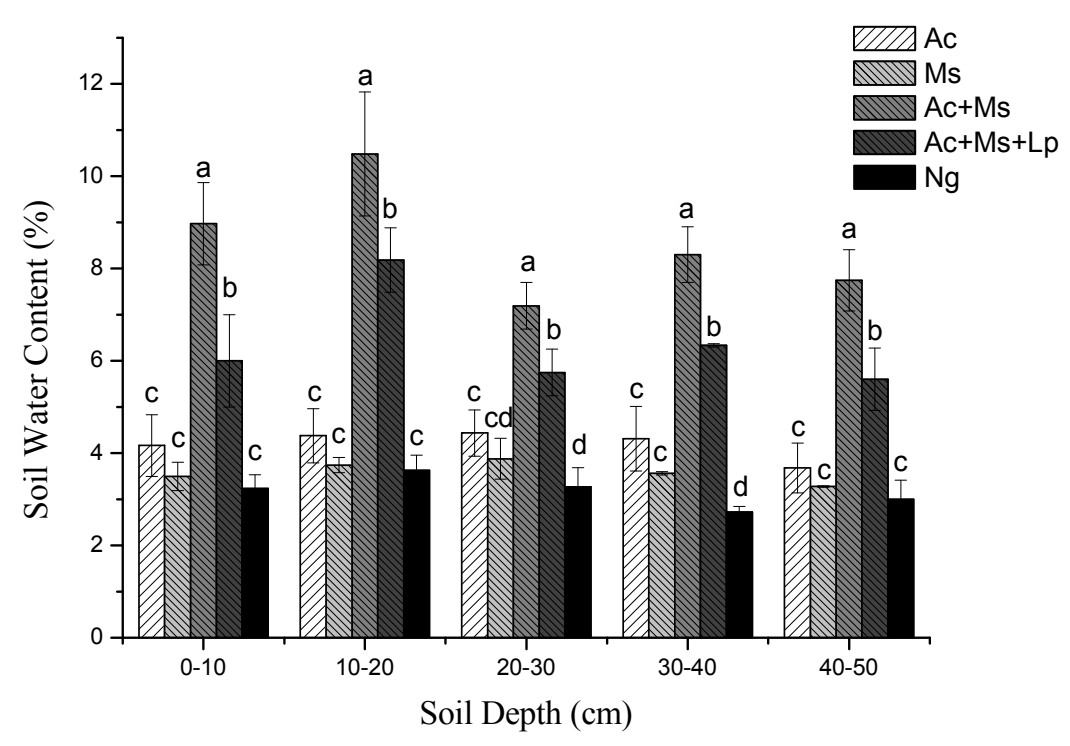

Figure 2. Effect of establishment of cultivated pastures on soil water content.

\subsection{Soil Organic Carbon}

As shown in Figure 3, the SOC in the different types of grasslands varied at different depths. In layer $0-10 \mathrm{~cm}$, the SOC storage capacity of the mixed culture of $A$. cristatum and M. sativa was higher than in the other seeded pastures, and significantly higher than it was in the adjacent enclosed natural grassland $(14.03 \%, p<0.05)$. In layer $10-20 \mathrm{~cm}$, the SOC in the monoculture of A. cristatum and the mixed culture of $A$. cristatum and $M$. sativa was significantly higher $(20.73 \%, 15.04 \%$, respectively) than that in the natural grassland $(p<0.05)$. In layer $20-30 \mathrm{~cm}$, the SOC in only the monoculture of A. cristatum was significantly higher than that in the natural grassland $(30.73 \%)$.

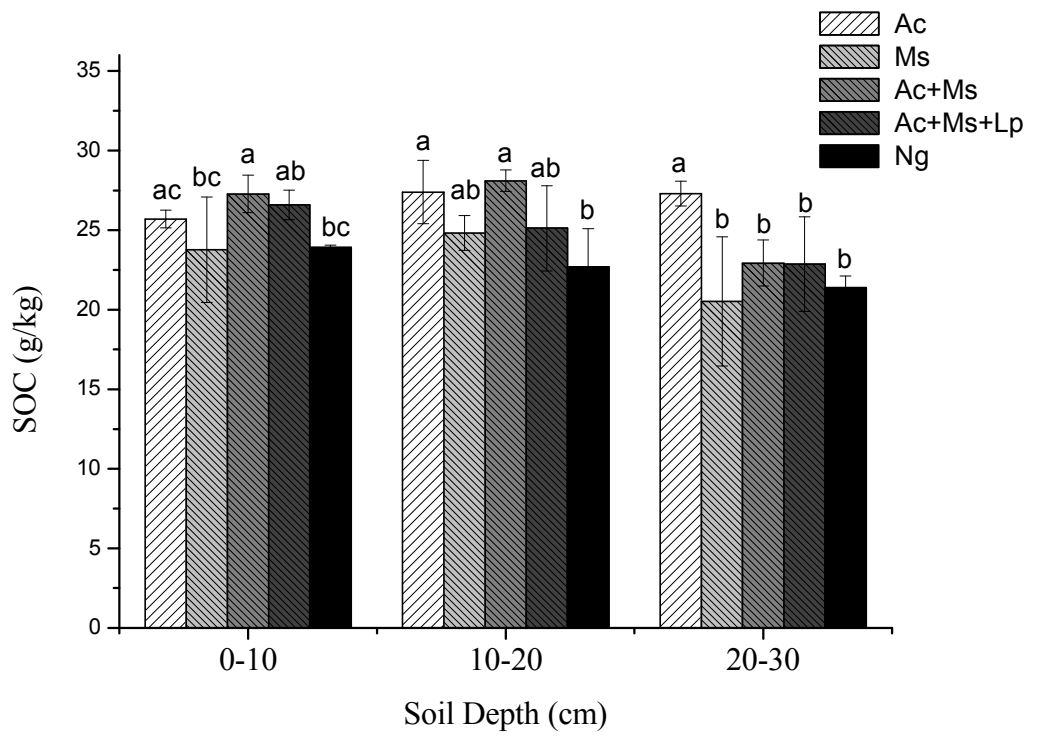

Figure 3. Effect of establishment of cultivated pastures on soil organic matter.

\subsection{Soil Total Nitrogen}

As shown in Figure 4, the STN in soil layer $0-10 \mathrm{~cm}$ did not differ significantly among all five types of grassland. In layer $10-20 \mathrm{~cm}$, the STN in the monoculture of A. cristatum and the mixed cultures of A. cristatum and M. sativa and of A. cristatum, M. sativa, and L. perenne were significantly higher $(22.74 \%, 28.87 \%$, and $22.39 \%$, respectively) than that in the adjacent enclosed natural grassland 
$(p<0.05)$. In layer $20-30 \mathrm{~cm}$, the STN in the monoculture of $A$. cristatum and the mixed culture of A. cristatum and M. sativa was significantly higher (32.59\% and $25.01 \%$, respectively) than it was in the natural grassland $(p<0.05)$.

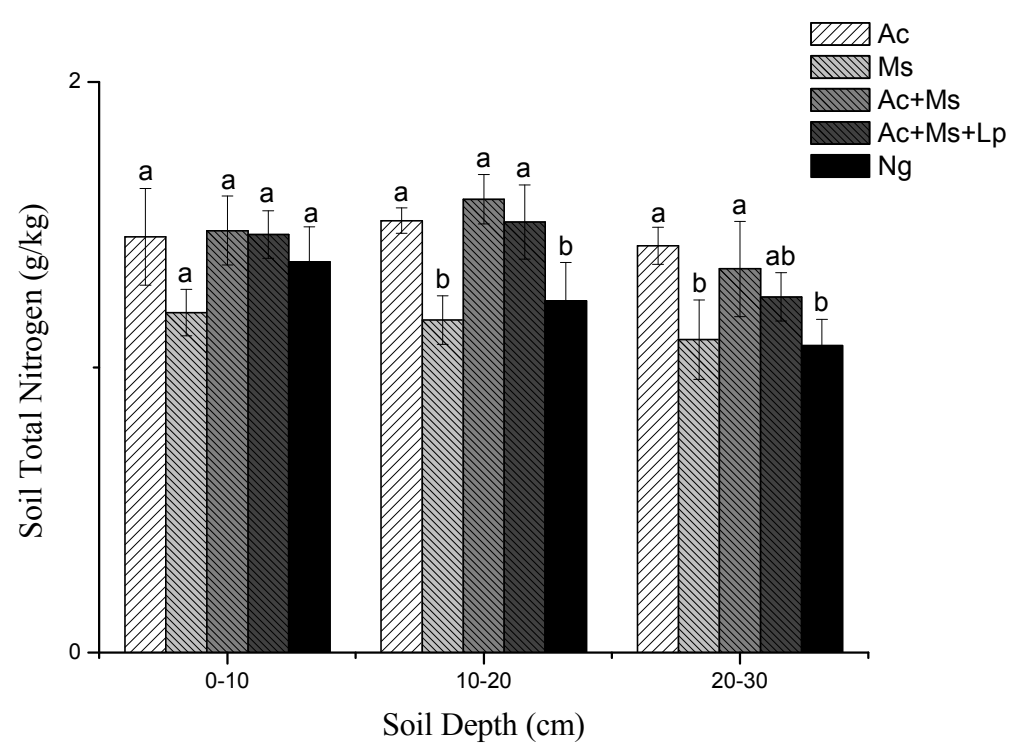

Figure 4. Effect of establishment of cultivated pastures on soil total nitrogen.

\section{Discussion}

\subsection{The Effects of Cultivated Pasture Establishment on Ecosystem Services Provisions Compared to Enclosed Grassland}

Cultivated pasture establishment can be a potentially effective land management tool to reverse grassland degradation and enhance forage production synchronously. In this study, we examined the two-year effects of cultivated pastures with different compositions of herbaceous species on four ecosystem service indicators, and compared them to another land use pattern, a grassland enclosure.

We found that the AGB in the four cultivated pastures was spectacularly higher than in the adjacent enclosed grassland, which may be due to the application of ammonium phosphate fertilizer. Nonetheless, it demonstrated that, with the implementation of agricultural measures, cultivated pasture can increase forage yield, at least in the short-term. Further, the mixed culture of A. cristatum and $M$. sativa produced the highest yield, which may be due to the niche and nutrition complementarity of grass and legume. Several previous studies also supported our conclusions. In a three-year continental-scale field experiment (31 sites primarily in continental Europe), Finn et al. (2013) found that four plant species mixtures with distinct functional types yielded more than the highest-yielding monoculture in agricultural grasslands managed most intensively [19]. In the Amazon forest of Brazil, cultivated pasture had a sufficiently high productivity in the first years after establishment; however, the incorporation of adapted forage legumes, the use of management systems, and moderate grazing pressure were the keys in maintaining the productivity of cultivated pasture for long periods of time [20]. In the semi-arid loess hilly-gully areas of the Loess Plateau, the aboveground productivity of Old World bluestem (Bothriochloa ischaemum) grassland was improved significantly by artificial cultivation, with a minimum increase of $20 \%$ over that of natural grassland [21]. On the saline lands of Qaidam Basin, cultivated pastures with a legume-grass mixed culture established on abandoned cropland yielded a forage output 51 times higher than that of natural grassland [22].

The SWC was also significantly higher in the cultivated pastures than in the adjacent enclosed grassland, especially for the two mixed cultures, implying that without irrigation, cultivated pasture can still improve SWC, which helps not only to alleviate soil water scarcity and enhance vegetation 
recovery, but also to conserve more soil and ameliorates the environmental damage from dust storms in this sub-arid region. Based on water scouring experiments on the Loess Plateau, cultivated pastures were found to play a role in water conservation by reducing runoff [23].

The improvement in the SOC in the cultivated pastures was less obvious. This may be due to the plowing practice, which loosens surface soil and enhances soil respiration. However, the monoculture of A. cristatum and the mixed culture of A. cristatum and M. sativa still produced significantly higher SOC than did the enclosed grassland in different soil layers. Based on ecosystem carbon flux research on nine European cultivated pastures in 2003-2004, Soussana et al. (2007) found that all cultivated pastures were carbon sinks, with an average carbon storage capacity of $-240 \pm 70 \mathrm{~g} \cdot \mathrm{C} \cdot \mathrm{m}^{-2} \cdot$ year $^{-1}$ [24]. Using a model simulation, Teixeira et al. (2011) found that the steady state, long-term SOM concentration in sown, rain-fed grasslands was higher than that in natural grasslands, and even fertilized natural grasslands in Portugal [25]. A statistically significant increase in SOC was also observed in all soil layers in a Digitaria decumbens pasture in Martinique after five years of establishment [26]. In their meta-analysis, Wang et al. (2011) found that 27 out of 37 previous studies on the conversion of freely grazed grassland to cultivated pasture showed increased SOC, with an average increase of $11.0 \%$ in China [27].

The improvement in the STN was also less obvious, with some species compositions showing a significant increase only in depth, even after application of ammonium phosphate. This also may be due to the plowing practice, which loosens soil and facilitates $\mathrm{N}$ leaching. In a multi-site field experiment conducted over three years (five sites spanning a climatic gradient from Atlantic to continental, and from temperate to arctic), Suter et al. (2013) found that the STN of grass-legume mixtures was on average greater than that of monocultures, and the effect was most pronounced when the proportion of legumes in the mixtures was approximately $60 \%$, and $30 \%$ of the STN originated from symbiotic $\mathrm{N}_{2}$ fixation [28]. Cultivated grassland establishment also resulted in significantly improved STN and phosphorus, especially in the $20-30 \mathrm{~cm}$ soil layer in a black-soil-type degraded grassland on the Tibetan Plateau [29].

We noticed that soil C:N ratios in three soil layers did not differ significantly significant among all five plots $(p>0.05)$, implying that the cultivated pastures produced no significantly different soil mineralization capability than did the enclosed grassland in the short-term, although some treatments produced significantly higher SOC, but STN only at depth, for example the mixed culture of A. cristatum and $M$. sativa This indicates that these plots are in the process of losing $\mathrm{N}$ through leaching, which would be a negative aspect of these treatments.

Overall, with care and attention to the limitations mentioned above, our experimental results suggested that cultivated pastures might have a positive effect on some of the pathways generating ecosystem services, at least in the short term. Thus, cultivated pasture establishment is potentially an effective approach in the restoration and rehabilitation of degraded grassland in China. However, we should be cautious, in that it could lead to a significant decrease in floral species richness and evenness [30,31]. Moreover, due to the short-term nature of this experiment, it is necessary to monitor the long-term effects. Some early studies have already provided positive results in this respect [32,33].

\subsection{Underlying Institutional and Socioeconomic Causes for the Underdevelopment of Cultivated Pasture in China}

In view of the current underdevelopment of grassland farming in China, a comprehensive analysis of the underlying institutional and socioeconomic causes is necessary, as it will allow us to reveal limiting factors and take corresponding countermeasures to enhance its development.

(1) Economic and institutional factors

Presently, the establishment of cultivated pasture in China is conducted largely via demonstration projects on the part of the government or NGOs, and few farmers plant grasses or forbs spontaneously. Economic incentives are the major obstacle. According to the cost-benefit analysis of our demonstration 
project, without irrigation, the average total annual cost of cultivated pasture is approximately $161 \mathrm{yuan} / \mathrm{mu}$, while the average annual total revenue of hay sales is $360 \mathrm{yuan} / \mathrm{mu}$ (see Table 2). Thus, the net benefit (199 yuan/mu) is significantly lower than that of planting crops, such as potato and maize, which have higher economic value (1055.86 yuan/mu and 316.24 yuan/mu, respectively, in 2013) [34].

Table 2. Average annual costs and benefits of cultivated pasture in the demonstration project of Duolun County 2013.

\begin{tabular}{cccc}
\hline Items & Sub-Items & Yuan $/ \mathbf{m u}$ & Notes \\
\hline \multirow{4}{*}{ Cost } & Plowing & 25 & \\
& Harrowing & 25 & \\
& Sowing & 15 & 28 yuan $/ \mathrm{kg} \times 2 \mathrm{~kg} / \mathrm{mu}$ \\
& Seed & 56 & 4.4 yuan $/ \mathrm{kg} \times 5 \mathrm{~kg} / \mathrm{mu}$ \\
& purchasing & 22 & \\
& Fertilizers & 18 & 1800 yuan $/$ ton $\times 0.2 \mathrm{ton} / \mathrm{mu}$ \\
\hline Benefit & Tending & 161 & \\
\hline & Total cost & 360 & \\
\hline
\end{tabular}

In this cost-benefit analysis, we only considered the benefit of hay sales. However, if cultivated pastures are established by farmers, they can use them either for direct grazing or forage, in which case they will save money from decreased feed consumption. Besides, if cultivated pastures increase the soil fertility as our experiment showed, farmers can introduce them into rotations and get better yields for complementary crops, which turn into more income. Moreover, some ecosystem service benefits generated by cultivated pastures should be regarded as positive externalities, such as carbon storage, which accrue to regional even global stakeholders but not farmers themselves. These external benefits should be paid by beneficiaries or government on their behalf, through direct purchases or subsidies.

Beginning in 2004, the Chinese government implemented a tax exemption and subsidies for growing grains, but not for growing grasses or forbs, and since then, the total area of cultivated pasture has declined. For example, the total area of cultivated pasture in Inner Mongolia at the end of 2010 was approximately 1.3 million ha less than that at the end of 2005 [35]. Even though the government has provided a subsidy of 150 yuan for each ha of cultivated pasture since 2011, this is still much lower than are the subsidies for growing grains. Moreover, water is the major limiting factor in arid and semi-arid regions of China, and investment in irrigation facilities and annual water costs are two major sources of expense in establishing cultivated pastures with irrigation.

It is also important to note that the scale of an operation is essentially the key factor that determines whether establishing cultivated pasture is profitable. Constrained by soil fertility and water availability, the average yield of cultivated pasture in China is generally no more than 3 tons per ha. This means that it is unlikely to be profitable unless it reaches a certain scale. Requests from large-scale operations for the purchase of large machinery, such as that for sowing and harvesting, increase the entry threshold for private farmers. In recent years, forage prices have risen, as represented by M. sativa. However, profits from growing grasses or forbs are still lower than those from growing grains because most Chinese farmers have small-holds.

The duration of hay harvesting in China is usually short, and is concentrated in late August and early September. Thus, the revenue is influenced directly by the level of mechanization in harvesting, and the larger the plot size, the higher the demand for mechanization. However, the level of mechanization in pastoral China is still relatively low, and most machines manufactured domestically are unsuitable for large-scale operations. Further, the purchase cost will increase if farmers turn to foreign machines, because they are not on the list of subsidies allowable for agricultural machinery. 
Compared to grains, sales channels for harvested hay are relatively narrow, and must be enhanced by establishing a grassland animal husbandry industrial chain comprised of a variety of upstream-downstream industries, such as grass planting and silage, forage processing, marketing, and transportation, livestock feeding, processing of animal products, transportation, and marketing.

(2) Technical factors

Conservation and restoration of grasslands dominated by native species has always been a priority, and can be used to prevent the spread of exotic or invasive species [36]. Hence, breeding seeds of native grass species is imperative. However, statistics show that the rate of self-sufficiency for grass seeds in Inner Mongolia was no more than $70 \%$ in 2010, and the remaining 30\% relies on imported seeds [35]. The adaptability of imported grass seeds to local climatic and environmental conditions, such as cold surges in the late spring, remains unverified.

An efficient system of technology extension services is also an important factor. Due to the lack of such services and expert guidance, farmers always choose grass species arbitrarily, and the species structure is rarely appropriate. According to statistics of the Agriculture and Animal Husbandry Department of Inner Mongolia, among all cultivated pastures, annual herbaceous species account for $41.48 \%$, perennials for $37.76 \%$, and fodder shrubs for $20.76 \%$; the proportion of annuals is too high [35].

\section{(3) Social factors}

In practice, we have found that the promotion of cultivated pasture is also impeded by awareness and acceptance on the part of herders. After thousands of years of nomadic life, herders in China have become accustomed to open grazing, and it will take time before they can adapt to a settled life and grass farming.

In additions, farmers are well known to be late adopters of technological innovations. Previous studies have shown that farmers' adoption of technology was correlated positively with their levels of education, scales of operation, household incomes, and access to technology extension services, among others [37,38]. All of these factors are also pertinent to cultivated pasture expansion and need some time to be nurtured in China.

\subsection{A Two-Step Development Strategy}

In light of the current levels of socio-economic and technological development in China, we suggest a two-step development strategy. The first is to promote rain-fed cultivated pasture on small-hold farms, which requires a relatively small amount of input costs for fertilizer and labor. Meanwhile, legislators should revise the Law of Land Administration and the Grassland Law to facilitate the free trade of grassland-contracted rights, and to foster large farms. In recent years, many farmers have migrated from rural areas to the cities to make a living, and have left their lands behind, so conditions for large-scale land operation are being met gradually. The agricultural subsidies policy also requires reformulation to provide equal opportunities to grow both grains and grasses (or forbs). In order to broaden the market for hay sales and improve the added value of animal products, it is imperative to foster a comprehensive industrial chain. Simultaneously, a comprehensive R\&D system should be established to focus on stable yield technologies, breeding native herbaceous species, and the development of grassland machinery that is adapted better to local terrains and climatic conditions. An efficient agricultural extension system also should be nurtured to provide training and disseminate relevant R\&D achievements and growing expertise. Given that, after thousands of years of nomadic life, herders in China have become accustomed to open grazing, it still will require time for them to adapt to a settled life and grassland farming. While above conditions and prerequisites are being met, the second step should be put forward: it is time to promote large-scale operations, which require significantly more input in land, irrigation, fertilizers, and machinery. 


\section{Conclusions}

As a comprehensive approach to sustain and potentially increase the delivery of ecosystem services to humans, practitioners have advocated recently for nature-based solutions [39], which was followed rapidly by a call for policy changes [40] to address increasing societal challenges. By building on and complementing traditional biodiversity conservation and management strategies, nature-based solutions integrate science, policy, and practice, and create biodiversity benefits in terms of diverse, well-managed ecosystems [41]. In this sense, developing cultivated pastures is connected strongly to ideas of nature-based solutions. A successful system of sown pastures developed in Portugal was referred to as a nature-based solution to environmental problems [42]. In our study, informed by field experiments and institutional and socioeconomic context analyses, our proposed two-step development strategy is poised to protect and restore degraded grasslands, modify grassland ecosystems to increase the quantity, quality, and sustainability of the particular services they provide, and contribute to bridge the gap between environmental protection and alleviation of poverty in China.

Future studies should focus on the long-term effects of cultivated pastures on all vital ecosystem services across various climatic, soil, and terrain conditions, identify more scientifically sound compositions of herbaceous species with wide-range functional types, and research key farming techniques or their optimized combinations for stable yields, and avoid any unexpected negative side effects on other ecosystem services.

Acknowledgments: This work was supported by the National Social Science Major Funding of China (Grant No. 15ZDA052), the National Natural Science Funding (Grant No. 71373209), and the National Key Technology R\&D Program of the Ministry of Science and Technology of China (Grant No. 2011BAC07B01-3). The authors sincerely thank the two anonymous reviewers for their constructive comments. The authors also thank Jiao Chen, Fei Fang, and Haili Xue for their insightful discussions.

Author Contributions: Haibin Chen and Haiping Tang conceived and designed the research; Li He and Haibin Chen performed the field experiment; Haibin Chen analyzed the data and wrote the paper; and Minjuan Zhao and Liqun Shao proofread, edited and revised the paper.

Conflicts of Interest: The authors declare no conflict of interest.

\section{References}

1. Sun, H.L. Ecosystems of China; Science Press: Beijing, China, 2005. (In Chinese)

2. Fang, J.Y.; Yang, Y.H.; Ma, W.H.; Mohammat, A.; Shen, H.H. Ecosystem carbon stocks and their changes in China's grasslands. Sci. China Life Sci. 2010, 53, 757-765. [CrossRef] [PubMed]

3. Zheng, X.X.; Liu, G.H.; Fu, B.J.; Jin, T.T.; Liu, Z.F. Effects of biodiversity and plant community composition on productivity in semiarid grasslands of Hulunbeir, Inner Mongolia, China. Ann. New York Acad. Sci. 2010, 1195, E52-E64. [CrossRef] [PubMed]

4. Kang, L.; Han, X.; Zhang, Z.; Sun, O.J. Grassland ecosystems in China: Review of current knowledge and research advancement. Philos. Trans. R. Soc. Lond. B 2007, 362, 997-1008. [CrossRef] [PubMed]

5. Li, S.G.; Harazono, Y.; Oikawa, T.; Zhao, H.L.; He, Z.Y.; Chang, X.L. Grassland desertification by grazing and the resulting micrometeorological changes in Inner Mongolia. Agric. Forest Meteorol. 2000, 102, 125-137.

6. Shi, P.; Yan, P.; Yuan, Y.; Nearing, M.A. Wind erosion research in China: past, present and future. Prog. Phys. Geogr. 2004, 28, 366-386. [CrossRef]

7. Waldron, S.; Brown, C.; Longworth, J. Grassland degradation and livelihoods in China's western pastoral region: A framework for understanding and refining China's recent policy responses. China Agric. Econ. Rev. 2010, 2, 298-320. [CrossRef]

8. Li, S.; Verburg, P.H.; Lv, S.; Wu, J.; Li, X. Spatial analysis of the driving factors of grassland degradation under conditions of climate change and intensive use in Inner Mongolia, China. Reg. Environ. Change 2012, 12, 461-474. [CrossRef]

9. Su, Y.Z.; Li, Y.L.; Cui, J.Y.; Zhao, W.Z. Influences of continuous grazing and livestock exclusion on soil properties in a degraded sandy grassland, Inner Mongolia, northern China. Catena 2005, 59, 267-278.

10. Wang, X.; Han, J.; Dong, Y. Recent grassland policies in China: An overview. Outlook Agric. 2005, 34, 105-110. [CrossRef] 
11. McNaughton, S.J. Grazing as an optimization process: Grass-ungulate relationships in the Serengeti. Am. Nat. 1979, 113, 691-703. [CrossRef]

12. Xue, R.; Zheng, S.X.; Bai, Y.F. Impacts of grazing intensity and management regimes on aboveground primary productivity and compensatory growth of grassland ecosystems in Inner Mongolia. Biodivers. Sci. 2010, 18, 300-311. (In Chinese)

13. Zhang, X.S. China must follow the path of the development of artificial grass and grassland farming. Impact Sci. Soc. 2010, 3, 18-21. (In Chinese)

14. Sollenberger, L.E.; Cherney, D.J.R. The Science of Grassland Agriculture; The Iowa State University Press: Ames, IA, USA, 2006.

15. Niu, S.L.; Jiang, G.M. Function of artificial grassland in restoration of degraded natural grassland and its research advance. J. Appl. Ecol. 2004, 15, 1662-1666. (In Chinese)

16. Hu, Z.Z. The importance of artificial grassland in the development of prataculture and the control of environment in China of 21 century. Grassl. Turf 2000, 27, 12-15. (In Chinese)

17. The Ministry of Agriculture, P.R.C. Grass Industry Sustainable Development Strategy in China; China Agriculture Press: Beijing, China, 2006. (In Chinese)

18. Millennium Ecosystem Assessment. Ecosystems and Human Well-Being: A Framework for Assessment; Island Press: Washington, DC, USA, 2005.

19. Finn, J.A.; Kirwan, L.; Connolly, J.; Sebastià, M.T.; Helgadottir, A.; Baadshaug, O.H.; Čop, J. Ecosystem function enhanced by combining four functional types of plant species in intensively managed grassland mixtures: A 3-year continental-scale field experiment. J. Appl. Ecol. 2013, 50, 365-375. [CrossRef]

20. Serrao, E.A.S.; Falesi, I.C.; Veiga, J.D.; Teixeira, N.J.F. Productivity of Cultivated Pastures on Low Fertility Soils in the Amazon of Brazil. In Pasture Production in acid Soils of the Tropics; CIAT: Cali, Colombie, 1979; pp. 195-225.

21. Xu, B.C.; Shan, L. Aboveground productivity and soil water characteristics of cultivated Old World bluestem grassland in semi-arid loess hilly-gully areas on the Loess Plateau. Pratacultural Sci. 2004, 21, 6-10. (In Chinese)

22. Qi, Y.L.; Liu, X.Q.; Li, Y. The ecological and economic benefits analysis on cultivated pastures established on abandoned croplands in Qaidam Basin. Prataculture Anim. Husb. 2008, 3, 10-13. (In Chinese)

23. Jiao, J.Y.; Wang, W.Z. The benefits of runoff and sediment reduction \& effective cover rate for soil and water conservation of artificial grassland on Loess Plateau. Acta Agrestia Sin. 2001, 9, 176-182. (In Chinese)

24. Soussana, J.F.; Allard, V.; Pilegaard, K.; Ambus, P.; Amman, C.; Campbell, C.; Flechard, C. Full accounting of the greenhouse gas $\left(\mathrm{CO}_{2}, \mathrm{~N}_{2} \mathrm{O}, \mathrm{CH}_{4}\right)$ budget of nine European grassland sites. Agric. Ecosyst. Environ. 2007, 121, 121-134. [CrossRef]

25. Teixeira, R.F.M.; Domingos, T.; Costa, A.P.S.V.; Oliveira, R.; Farropas, L.; Calouro, F.; Carneiro, J.P.B.G. Soil organic matter dynamics in Portuguese natural and sown rainfed grasslands. Ecol. Model. 2011, 222, 993-1001. [CrossRef]

26. Chevallier, T.; Voltz, M.; Blanchart, E.; Chotte, J.L.; Eschenbrenner, V.; Mahieu, M.; Albrecht, A. Spatial and temporal changes of soil $\mathrm{C}$ after establishment of a pasture on a long-term cultivated vertisol (Martinique). Geoderma 2000, 94, 43-58. [CrossRef]

27. Wang, S.; Wilkes, A.; Zhang, Z.; Chang, X.; Lang, R.; Wang, Y.; Niu, H. Management and land use change effects on soil carbon in northern China's grasslands: A synthesis. Agric. Ecosyst. Environ. 2011, 142, 329-340. [CrossRef]

28. Suter, M.; Connolly, J.; Finn, J.A.; Helgadóttir, Á.; Kirwan, L.; Loges, R.; Hopkins, A. Grass-legume mixtures enhance yield of total nitrogen and uptake from symbiotic N2 fixation: Evidence from a three-year multisite experiment. In the Role of Grasslands in a Green Future: Threats and Perspectives in Less Favoured Areas; Proceedings of the 17th Symposium of the European Grassland Federation, Akureyri, Iceland, 23-26 June 2013; Agricultural University of Iceland: Hvanneyri, Iceland, 2013; pp. 76-78.

29. Wu, G.L.; Liu, Z.H.; Zhang, L.; Hu, T.M.; Chen, J.M. Effects of artificial grassland establishment on soil nutrients and carbon properties in a black-soil-type degraded grassland. Plant Soil 2010, 333, 469-479. [CrossRef]

30. Török, P.; Deák, B.; Vida, E.; Valkó, O.; Lengyel, S.; Tóthmérész, B. Restoring grassland biodiversity: Sowing low-diversity seed mixtures can lead to rapid favourable changes. Biol. Conserv. 2010, 143, 806-812. [CrossRef] 
31. Jones, C.C.; Dreyer, G.D.; Barrett, N. Evaluating the Success of Seed Sowing in a New England Grassland Restoration. Nat. Areas J. 2013, 33, 214-221. [CrossRef]

32. Gómez-Rey, M.X.; Garcês, A.; Madeira, M. Soil organic C accumulation and N availability under improved pastures established in Mediterranean oak woodlands. Soil Use Manag. 2012, 28, 497-507.

33. Gómez-Rey, M.X.; Madeira, M.; Gonzalez-Prieto, S.J.; Coutinho, J. Soil C and N dynamics in a Mediterranean oak woodland with shrub encroachment. Plant Soil 2013, 371, 339-354. [CrossRef]

34. Price Department, the National Development and Reform Commission, People's Republic of China. Data Compilation of Costs and Benefits of Agricultural Products in China; China Statistics Press: Beijing, China, 2014. (In Chinese)

35. The Department of Agriculture and Animal Husbandry, Inner Mongolia Autonomous Region, People's Republic of China. The Twelfth Five Year Plan for Cultivated Pasture Establishment of Inner Mongolia Autonomous Region; The Department of Agriculture and Animal Husbandry, Inner Mongolia Autonomous Region: Hohhot, China, 2011. (In Chinese)

36. Sheley, R.L.; Half, M.L. Enhancing native forb establishment and persistence using a rich seed mixture. Restor. Ecol. 2006, 14, 627-635. [CrossRef]

37. Atanu, S.; Love, H.A.; Schwart, R. Adoption of emerging technologies under output uncertainty. Am. J. Agric. Econ. 1994, 76, 836-846.

38. Khanna, M. Sequential adoption of site-specific technologies and its implications for nitrogen productivity: A double selectivity model. Am. J. Agric. Econ. 2001, 83, 35-51. [CrossRef]

39. International Union for Conservation of Nature (IUCN). No Time to Lose: Make Full Use of Nature-Based Solutions in the Post-2012 Climate Change Regime; IUCN: Gland, Switzerland, 2009.

40. European Commission. Towards an EU Research And Innovation Policy Agenda for Nature-Based Solutions $\mathcal{E}$ Re-Naturing Cities; Final Report of the Horizon 2020 expert group on nature-based solutions and re-naturing cities; European Commission: Brussels, Belgium, 2015.

41. Eggermont, H.; Balian, E.; Azevedo, J.M.N.; Beumer, V.; Brodin, T.; Claudet, J.; Reuter, K. Nature-based Solutions: New Influence for Environmental Management and Research in Europe. GAIA-Ecol. Perspect. Sci. Soc. 2015, 24, 243-248. [CrossRef]

42. Teixeira, R.F.; Proença, V.; Crespo, D.; Valada, T.; Domingos, T. A conceptual framework for the analysis of engineered biodiverse pastures. Ecol. Eng. 2015, 77, 85-97. [CrossRef]

(C) 2016 by the authors; licensee MDPI, Basel, Switzerland. This article is an open access article distributed under the terms and conditions of the Creative Commons Attribution (CC-BY) license (http://creativecommons.org/licenses/by/4.0/). 